\title{
Attenuation of a Turkeypoxvirus field strain as an alternative to heterologous vaccination in turkeys
}

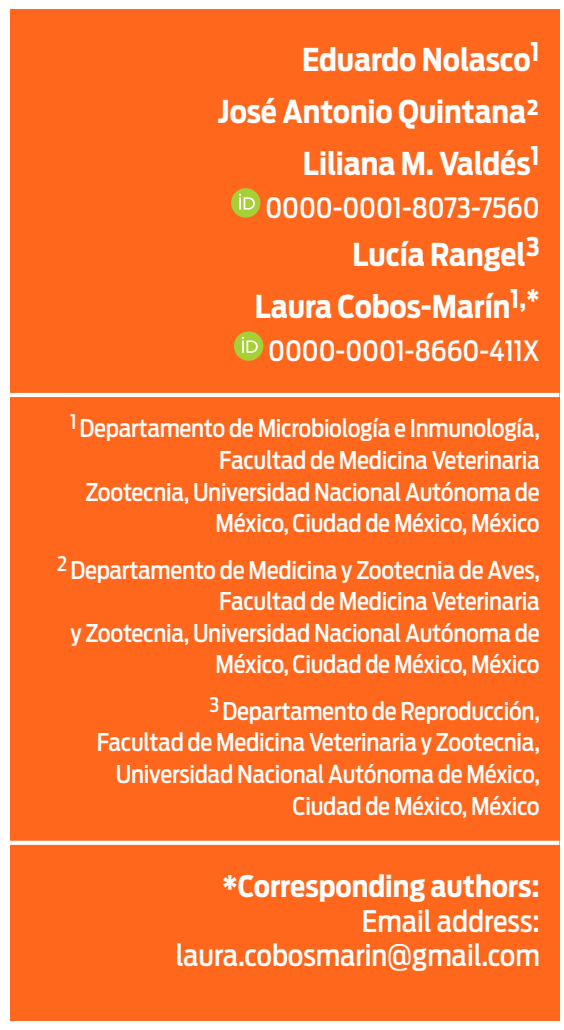

Published: $\quad 2020-12-18$

@ Copyright 2020 Eduardo Nolasco et al. open access $\boldsymbol{\gamma}$

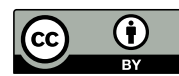

Distributed under Creative Commons CC-BY 4.0

\begin{abstract}
Avian pox can severely impact turkey production systems. Vaccination programs in Mexico use commercially available Fowlpoxvirus vaccines, that are used across different bird species. Nonetheless, there are reports of sporadic disease outbreaks among vaccinated turkeys, which suggest that heterologous vaccines may provide limited immunity, presenting the need to develop homologous vaccines that can better protect turkeys.

This study compared the protection granted to turkey chicks by a commercial Fowlpoxvirus vaccine and by a live attenuated Turkeypoxvirus vaccine after a challenge with a field isolated Turkeypoxvirus virus.

Histopathology, polymerase chain reaction, and sequencing of DNA were used for viral identification. A Turkeypoxvirus strain was first isolated in chicken embryo lesions, and subsequently adapted through serial passes in chorioallantoic membrane to produce the homologous vaccine. The attenuated virus was used as a vaccine when a 104.4 embryo $I D_{50} / \mathrm{mL}$ titre was reached.

Three groups of three-week-old turkey chicks were used for challenge experiments. Subjects in Group 1 were immunized with the attenuated Turkeypoxvirus vaccine (homologous vaccine). Chicks in Group 2 were vaccinated with the commercially available heterologous vaccine (Fowlpoxvirus). Subjects in Group 3 were not vaccinated and received only saline solution (control group). Two weeks after vaccination, animals from Group 1 reached a $97.7 \mathrm{ND}_{50}$ seroneutralization titre, while levels reached in Group 2 birds and in control chicks were $11.7 \mathrm{ND}_{50}$ (Group 2) and zero, respectively. At this time, all groups were challenged with a suspension of a field-isolated Turkeypox virus. The homologous vaccine afforded 100\% protection in Group 1 (10/10 individuals), while only 10\% (1/10) of individuals in Group 2 were protected by the commercial heterologous Fowlpoxvirus vaccine. None of the non-immunized birds in Group 3 were protected (0/10).
\end{abstract}

\section{Cite this as:}

Nolasco E, Quintana JA, Valdés LM, Rangel L, Cobos-Marín L. Attenuation of a Turkeypoxvirus field strain as an alternative to heterologous vaccination in turkeys. Veterinaria México OA. 2020;7(4). doi: 10.22201/fmvz.24486760e.2020.4.896 
These results show that the homologous vaccine afforded a greater protection against a Turkeypox virus infection than that observed for the heterologous vaccine, and that a homologous vaccine can be efficiently produced by isolating and attenuating the virus from turkeypox lesions, through chorioallantoic membrane serial passes.

Keywords: Turkey; Vaccine; Poxvirus 


\section{Introduction}

Domestic turkeys (Meleagris gallopavo gallopavo) are the second most important species for Mexican poultry husbandry, after the meat and egg-laying chicken varieties (Gallus gallus), reaching an average year production of close to 15,000 tonnes of meat. ${ }^{1-4}$

Similar to other species of birds, such as chickens, pigeons, canaries and psittacids, turkeys are susceptible to avian pox infections. ${ }^{3}$ Avian pox is caused by a DNA virus of the genus Avipoxvirus, family Poxviridae, and has two main presentations: the cutaneous or dry form is the most common and is characterized by proliferative lesions and scabs on the skin that can develop into secondary bacterial infections. The diphtheritic or wet form is characterized by proliferative lesions in the nasal conducts, larynx, and trachea that cause dyspnoea and death by asphyxia. There is a third systemic form, that is exclusive to canaries, and causes hepatic necrosis, pulmonary nodules, and high mortality. 5 For the cutaneous and diphtheritic forms mortality is low, but the disease can heavily impact meat and egg production, causing considerable economic losses. ${ }^{3}$

The ten extant species of Avipoxvirus (www.ictvonline.org) can be classified in at least three clades, A, B, and C, based on the $4 \mathrm{~b}$ core protein gene. ${ }^{6-8}$ The specific differences among viruses in each clade are not known, as complete genomic sequences are available only for Fowlpoxvirus, in clade $\mathrm{A}^{9}$ and Canarypoxvirus, in clade B (10), which show only a 70\% sequence identity. Since Fowlpoxvirus (from chickens) and Turkeypoxvirus (from turkeys) belong to the same clade and subclade (A1), it is thought that they exhibit a high degree of homology. However, variations in their genetic sequences could be significant enough to elicit changes in their antigenicity.

Where avian pox is endemic, the best way to prevent it is through vaccination. The wing web method is preferred for chickens, while the loose skin on the thigh and abdomen is preferred for turkey immunization. ${ }^{3}$ There are specific vaccines for chickens, turkeys, and pigeons, among other birds; however, commercially available vaccines in Mexico are derived exclusively from Fowlpoxvirus. These are applied to chickens and hens (homologous vaccination), as well as quails and turkeys, and basically any other bird species (heterologous vaccination). Nonetheless, studies have shown that homologous vaccines provide better protection than heterologous vaccines. ${ }^{1-13}$ Indeed, turkey avian pox outbreaks have been reported by farmers that apply the commercially available heterologous vaccine against chicken poxvirus (unpublished observations).

Due to the low efficacy of heterologous vaccines, the wide distribution of the disease, and the importance of turkey meat production in Mexico, an effective vaccine is needed. The objective of this study was to assess whether attenuation of a Turkeypoxvirus strain can be effective in controlling infection following a challenge with a field virus, and to compare immunization titres with those achieved in subjects immunized with a commercial chicken poxvirus vaccine. We hypothesized that vaccinating turkeys with a homologous attenuated pox virus would result in greater protection than that obtained by the commercially available chicken poxvirus vaccine. 


\section{Materials and methods}

Isolation and identification of the Turkeypoxvirus were performed following the Laboratory manual for the isolation, identification, and characterization of avian pathogens by the American Association of Avian Pathologists. ${ }^{14}$

\section{Virus isolation}

Scabs from turkeys showing early pox lesions from a naturally occurring infection were collected and subsequently ground, adding phosphate buffer solution (PBS), to obtain an $80 \%$ suspension. This suspension was then centrifuged at $600 \times \mathrm{g}$ for 10 minutes, the supernatant was decanted and filtered through $0.45 \mu \mathrm{m}$ filters, and antibiotics were added to supress bacterial contamination (penicillin and streptomycin 10,000 IU and $10 \mathrm{mg} / \mathrm{mL}$, respectively). Absence of contamination was later confirmed through a bacterial sterility test, inoculating $0.1 \mathrm{~mL}$ of the viral suspension in bacteriological media (blood agar and thioglycolate broth), and incubated for 48 hours at $37^{\circ} \mathrm{C}$.

Ten to twelve-day-old specific pathogen-free (SPF) chicken embryos were inoculated with $100 \mu \mathrm{L}$ of the viral suspension, using the chorioallantoic membrane (CAM) as the route of administration through the false air cell method. Embryos were subsequently incubated at $37{ }^{\circ} \mathrm{C}$ for 5 days and monitored daily for mortality. At day 5, embryos were euthanized through cooling (two hour freezing) to obtain the CAMs. Membranes showing edema were selected and ground under sterile conditions. The resulting suspension was centrifuged at $600 \times \mathrm{g}$ for $10 \mathrm{~min}-$ utes, and the supernatant was collected. A second bacterial sterility test was then performed using the obtained supernatant, to ensure absence of contamination. Subsequent blind passes of the suspension on chicken embryo CAM followed, until typical avian pox lesions (white pustules and edema on the chorioallantoic membrane) were observed. ${ }^{14}$

\section{Histopathological identification}

Hematoxylin and eosin-stained histological sections of CAM membranes showing early Avipoxvirus lesions were examined for intracytoplasmic inclusion bodies (Bollinger bodies), which are characteristic of Avipoxivirus infection.

\section{Molecular identification}

The polymerase chain reaction (PCR) technique was used to amplify a 578 bp fragment of the $4 b$ protein gene of the avian pox virus, to ensure that the infection had been caused by an Avipoxvirus. ${ }^{15}$

DNA was extracted from $25 \mathrm{mg}$ of CAM with pox lesions. Briefly, the tissue was homogenized with $1 \mathrm{~mL}$ of lysis solution and centrifuged at $10,000 \times \mathrm{g}$ for 10 minutes. The supernatant was decanted to a test tube, $0.5 \mathrm{~mL}$ of $100 \%$ ethanol were added, followed by a 3-minute incubation period. The dilution was then centrifuged at $4,000 \times \mathrm{g}$ for 2 minutes and the supernatant was discarded. The remaining pellet was subsequently rinsed on two occasions by adding $1 \mathrm{~mL}$ of $75 \%$ ethanol, centrifuging at 4,000 $\times \mathrm{g}$ for 2 minutes, and discarding the supernatant on each instance. The resulting pellet containing DNA was then heated to $65^{\circ} \mathrm{C}$ for 
5 minutes and allowed to dry. Finally, the pellet was dissolved in $100 \mu \mathrm{L}$ of water for injection. ${ }^{12}$

The final reaction volume for the PCR was $25 \mu \mathrm{L}$ containing $1 \mu \mathrm{g}$ of DNA, 1.5 units of Taq polymerase, $1.5 \mathrm{mM}$ of MgCl2, $200 \mu \mathrm{M}$ of dNTPs, 1X of Reg 10X, and 12.5 pmol of each of the primers described by Lee \& Lee (1997) (P1:5'-CAGCAGGTGCTAAACAACAA-3'; P2:5'-CGGTAGCTTAACGCCGAATA-3'). ${ }^{15}$

The PCR reaction was executed with a first denaturation cycle at $94{ }^{\circ} \mathrm{C}$ for 5 minutes, followed by 30 cycles of denaturation at $94^{\circ} \mathrm{C}$ for 30 seconds, annealing at $52{ }^{\circ} \mathrm{C}$ for 30 seconds, and extension at $72{ }^{\circ} \mathrm{C}$ for 30 seconds, finishing by a last extension cycle at $72{ }^{\circ} \mathrm{C}$ for 5 minutes. ${ }^{12}$

Four $\mu \mathrm{L}$ of PCR products were run in a $1.5 \%$ agarose gel at 90 volts for 45 minutes. The gel was stained with $0.01 \%$ ethidium bromide for 20 minutes and then visualized in a UV transilluminator. A reaction mix with no sample added was used as a negative control.

\section{Sequencing}

The purified PCR product was sent for sequencing by the Sanger method (16) to the Instituto de Biotecnología at the UNAM, to guarantee that the isolated viral DNA matched the turkey Avipoxvirus (Turkeypoxvirus).

\section{Development of the homologous vaccine}

The CAMs that presented suggestive poxvirus infection lesions after to the isolation step were used to prepare a viral suspension that was then inoculated into chicken embryos. Serial passes were performed, until the lesions were conspicuous. The virus was subsequently titrated by the Reed-Muench method. ${ }^{17} \mathrm{~A}$ pool of all CAMs that presented poxvirus lesions were used to prepare the vaccine viral suspension that had a titre of at least 104 embryo infectious doses 50\% (embryo ID50/mL). ${ }^{14}$

\section{Animals and vaccination procedure}

Three-week old turkeys from the CEFOA farm (Centro Nacional de Innovación en Agricultura del Altiplano y Especies Menores) in Tlaxcala were used. After selection, birds were randomly divided into 3 groups of 10 individuals each, which were immediately transported in ventilated boxes to either an isolated $12 \mathrm{~m}^{2}$ pen placed within a poultry hut in the same CEFOA farm in Tlaxcala (10 birds), or to $12 \mathrm{~m}^{2}$ pens placed in two isolated separate rooms (10 chicks in each pen) within the same building, at the Immunology and Microbiology Department of the veterinary school, UNAM in Mexico City. All animals were housed under a $16 \mathrm{~h}$ light: $8 \mathrm{~h}$ dark schedule and were given water and the same commercial food ad libitum throughout the experimental period. Chicks were allowed to adapt to their living conditions for 5 days prior to inoculation.

Blood samples were taken from the radial vein of the wing from all individuals, with a syringe fitted with a 22-gauge needle, on the day prior and 15 days after vaccination, but previous to the field virus challenge. To obtain sera, samples were transferred to $10 \mathrm{ml}$ tubes, transported at $4{ }^{\circ} \mathrm{C}$ to the laboratory and centrifuged at $3000 \mathrm{rpm}$ for $10 \mathrm{~min}$. Samples were then frozen at $-20^{\circ} \mathrm{C}$ until use. 
Animal procedures were approved by the Ethics and Animal Welfare Committee of the veterinary school, UNAM.

\section{Experimental groups}

1 Group 1 (homologous vaccine): ten turkey chicks were immunized with a $0.01 \mathrm{~mL}$ dose of the experimental homologous Turkeypoxvirus vaccine prepared for this study. Vaccination was performed with a double-prong needle in the loose skin of the thigh. Animals from this group were housed at an isolated room of the Immunology and Microbiology Department at the Veterinary School, UNAM in Mexico City.

- Group 2 (heterologous vaccine): ten turkey chicks were inoculated with a $0.01 \mathrm{~mL}$ single dose of the commercial chicken poxvirus vaccine. The vaccine was applied with a double-prong needle in the loose skin of the thigh following manufacturer specifications. These animals remained in the CEFOA farm in Tlaxcala.

- Control group: ten unvaccinated turkey chicks were kept in an isolated room at the Immunology and Microbiology Department at the Veterinary School, UNAM, in Mexico City until challenged with the Turkeypox field virus. A $0.01 \mathrm{~mL}$ saline solution injection was applied with a double-prong needle in the loose skin of the thigh.

\section{Field virus challenge}

To test the potency of both the homologous and the heterologous vaccines, the three experimental groups were challenged two weeks after vaccination in their respective locations with the isolated pox virus from naturally infected turkeys at the Tlaxcala CEFOA farm. Individuals were challenged by inoculation through an excoriation on the thigh and kept under daily observation to identify the development of suggestive smallpox lesions in the inoculation area through the three following weeks. Subjects that did not develop suggestive lesions were considered protected. Effectiveness of the vaccine was established at a minimum of $80 \%$ protection of challenged individuals.

\section{Viral seroneutralization}

The seroneutralizing antibody titres against Avipoxvirus in the treatment groups were determined before and after vaccination through the $\beta$ method ${ }^{18}$ with a 100 embryo $\mathrm{ID}_{50} / \mathrm{mL}$ of Turkeypoxvirus. Two $\mathrm{mL}$ of blood were drawn from every individual on the first day of confinement and one day prior to the field-virus challenge. Sera was separated through incubation of blood samples at $37^{\circ} \mathrm{C}$ for $4 \mathrm{~h}$, and then frozen at $-20^{\circ} \mathrm{C}$ until use. Sera from birds within each experimental group were subsequently pooled and then inactivated at $56{ }^{\circ} \mathrm{C}$ for 30 minutes. Eight serial double dilutions followed, beginning at a $1 / 5$ dilution. Each dilution was incubated for 30 minutes at room temperature with the turkey virus. The serum-virus mix was finally inoculated into chicken embryo CAMs, 5 embryos per dilution, and the antibody titre was calculated with the Reed-Muench statistical method. ${ }^{17}$ 


\section{Results and discussion}

The viral suspension obtained from ground scabs tested negative for bacterial contamination. After two blind passes on chicken embryos, the presence of lesions such as edema, erythema, white pustules, and thickened chorioallantoic membranes was suggestive of a poxvirus infection.

Histological sections of chorioallantoic membranes showed both hyperplasia and hydropic degeneration of the epithelium, as well as eosinophilic intracytoplasmic inclusion bodies (Figure 1).

PCR from lesions on turkeypoxvirus-infected chicken embryo chorioallantoic membranes resulted in a 578 bp amplification fragment, consistent with what is expected for the known $4 \mathrm{~b}$ protein of avian pox (Figure 2).

Sequencing of the purified PCR product showed a 99\% identity with Turkeypoxvirus TKPV-HU1124/201, sequence ID: KP7281 10.2; using BLAST-NCBI (see supplementary Figure 1).

To develop the homologous vaccine, 12 serial passes on chicken embryo chorioallantoic membranes were performed, resulting in a viral suspension with a 104.4 embryo ID50/mL virus titre, that was used to inoculate birds in this study. The embryo ID50 value obtained is similar to the one reported by Sánchez et al. in their study (104.3 embryo ID50/mL), which proved to be successfully used for vaccinations. ${ }^{12}$

Response to inoculation with the homologous vaccine was verified through observation of local lesions such as reddening, papules, and scabs. All subjects in immunized groups showed this response, starting day 10 postvaccination, while none of the control subjects presented with this type of lesions.

When challenged with the field-virus, 100\% of the unvaccinated group presented lesions on the site of inoculation (10/10), which expanded radially during the three weeks of observation (Figure $3 \mathrm{~A}$ ). Also, $90 \%$ of the birds $(9 / 10)$ that received the commercial heterologous vaccine developed pox lesions after being challenged, similar to those seen in the unvaccinated control group (Figure 3B). Conversely, none $(0 / 10)$ of the subjects in the homologous vaccine group showed pox lesions after being challenged with the field-isolated virus (Figure 3C).

Taken together these results show a 100\% protection rate achieved in subjects vaccinated with the homologous vaccine, compared to a 10\% protection rate afforded with the commercial Fowlpoxvirus vaccine. Similarly, Winterfield et al. ${ }^{11,19}$ found that heterologous vaccination of turkeys with pigeon or chicken virus granted only a $0.9 \%$ and $0.8 \%$ protection respectively, against a Turkeypoxvirus challenge, while the homologous vaccination protected $100 \%$ of the subjects. Correspondingly, a more recent study on pigeons by Sánchez et al. ${ }^{12}$ showed that homologous vaccination affords greater protection than heterologous vaccination, as the commercial Fow/poxvirus vaccine did not protect pigeons against a challenge with pigeon virus, even when 55\% of individuals showed post-vaccination reactions, while a homologous vaccine granted a 100\% protection rate. Furthermore, heterologous vaccination has also been shown to provide only temporary protection since turkeys vaccinated with a chicken poxvirus that had been cultured in chicken embryos experienced a $40 \%$ reduction in this protection in only three months. ${ }^{13}$ Conversely, Sarma et al. ${ }^{20}$ found high efficacy of vaccines obtained from chicken virus and administered to turkeys ( $98 \%$ protection rate). Nonetheless, it should be noted that subjects in that study were challenged with the chicken and not the turkey virus. 


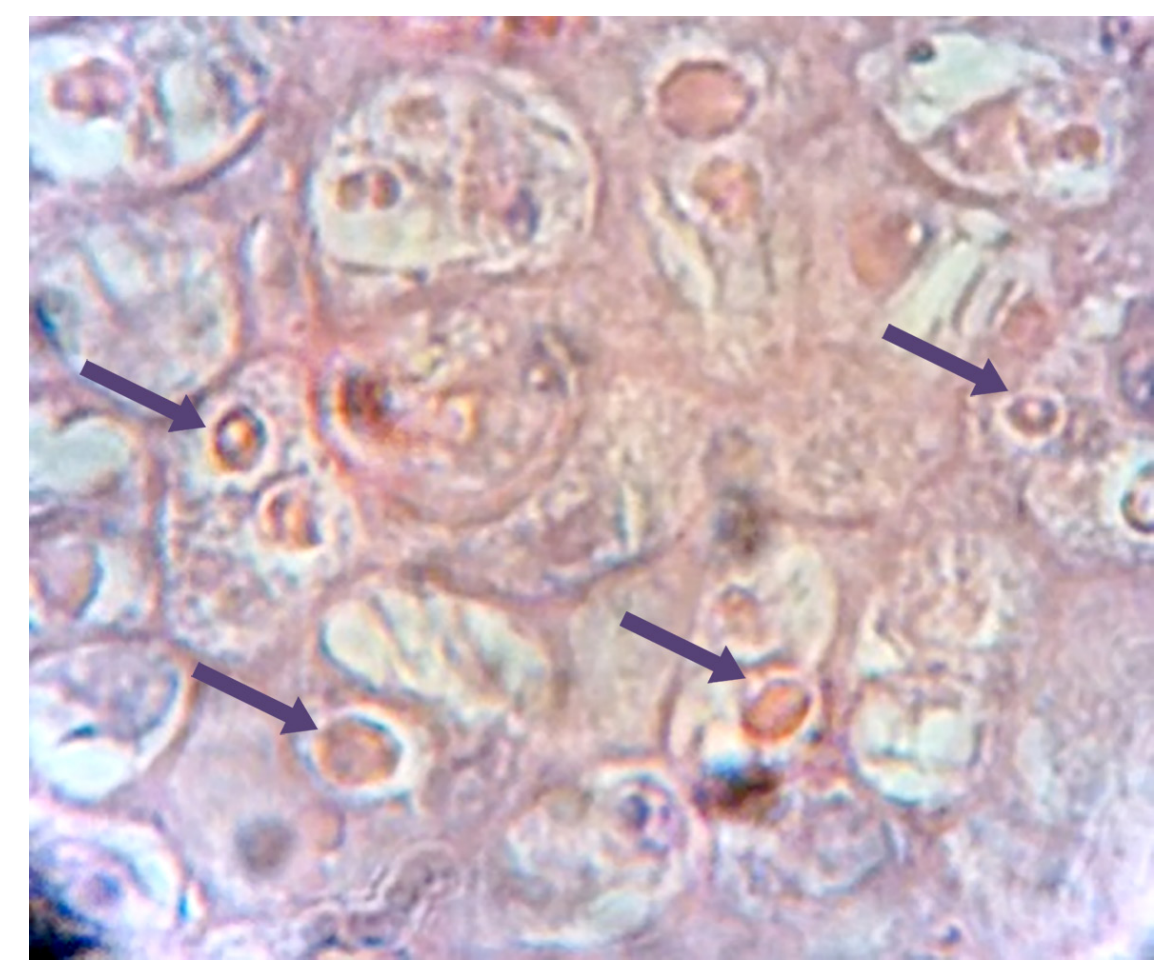

Figure 1. A hematoxylin and eosin-stained slide of a Chorioallantoic membrane from a chicken embryo infected with the Turkeypoxvirus. Yellow arrows show multiple intracytoplasmic inclusion bodies. 40x.

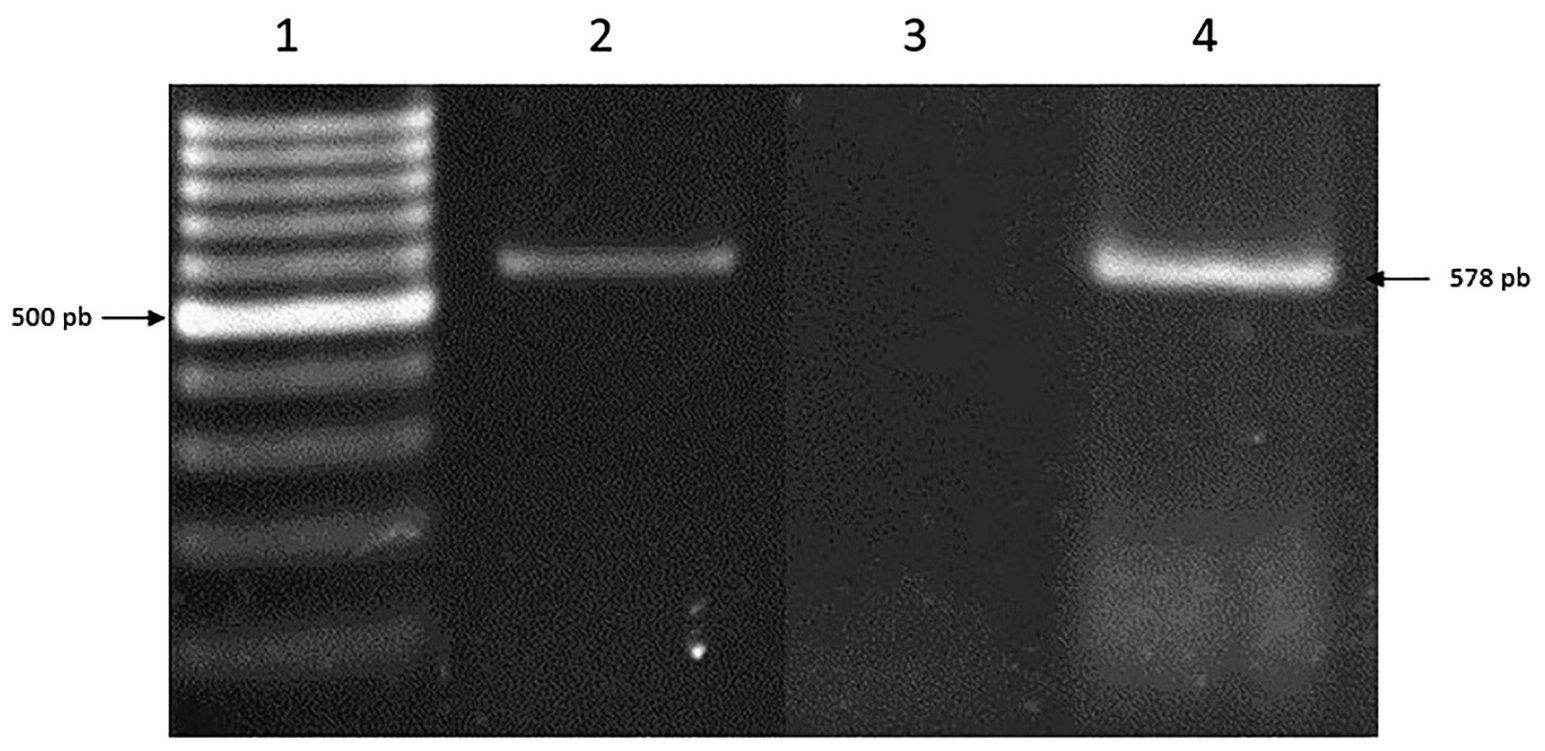

Figure 2. Electrophoresis of PCR amplification products in a 1.5\% agarose gel. Lanes: 1) 100 bp molecular weight marker. 2) DNA amplification fragment obtained from chorioallantoic membranes infected with a Turkeypoxvirus isolated from the scabs of diseased individuals. 3) negative control. 4) positive control, DNA amplification fragment obtained from Fowlpoxvirus from a commercially available vaccine. 

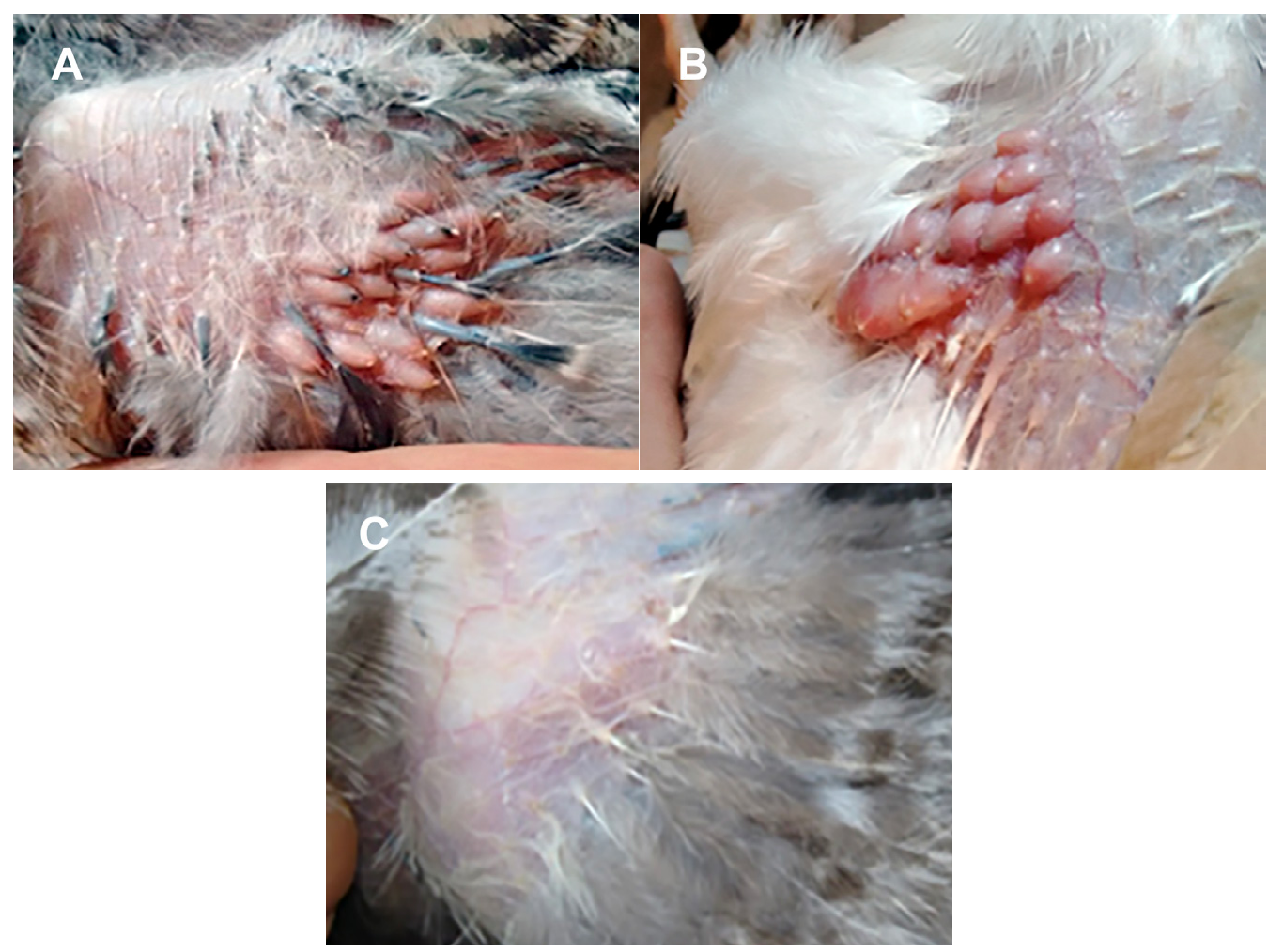

Figure 3. Photographs of the thigh region of eight-week-old turkey chicks from the three treatment groups after being challenged through an excoriation with a turkeypoxvirus isolate. A) Control. B) Heterologous vaccine. C) Homologous vaccine. Lesions consistent with a pox infection can be seen in A and B. No post-challenge lesions are observed in photograph $\mathrm{C}$.

\begin{tabular}{|c|c|c|c|c|c|c|}
\hline \multicolumn{4}{|c|}{ ange 1: 130028 to 130565 GenBank Graphics } & \multicolumn{3}{|c|}{$\nabla$ Next Match $\Delta$ Previous Matcl } \\
\hline \multicolumn{2}{|c|}{$\begin{array}{l}\text { Score } \\
965 \text { bits }(522)\end{array}$} & $\begin{array}{l}\text { Expect } \\
0.0\end{array}$ & $\begin{array}{l}\text { Identities } \\
533 / 538(99 \%)\end{array}$ & $\begin{array}{l}\text { Gaps } \\
1 / 538(0 \%)\end{array}$ & $\begin{array}{l}\text { Strand } \\
\text { Plus/Minus }\end{array}$ & \\
\hline Query & 8 & \multirow{2}{*}{\multicolumn{4}{|c|}{ 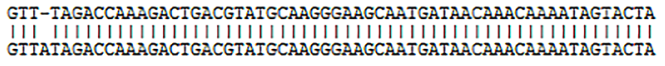 }} & 66 \\
\hline bjet & 130565 & & & & & 130506 \\
\hline uery & 67 & \multirow{2}{*}{\multicolumn{4}{|c|}{ 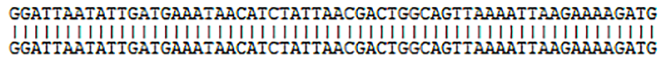 }} & 126 \\
\hline bjct & 130505 & & & & & 130446 \\
\hline uery & 127 & \multirow{2}{*}{\multicolumn{4}{|c|}{ 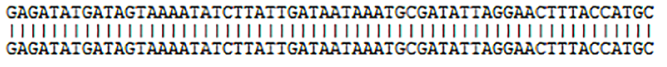 }} & 186 \\
\hline ojet & 130445 & & & & & 130386 \\
\hline Uery & 187 & \multirow{2}{*}{\multicolumn{4}{|c|}{ 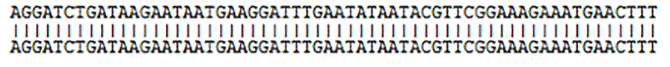 }} & 246 \\
\hline bjet & 130385 & & & & & 130326 \\
\hline Uery & 247 & \multirow{2}{*}{\multicolumn{4}{|c|}{ 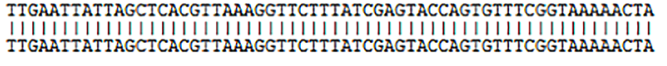 }} & 30 \\
\hline ojet & 1303 & & & & & \\
\hline uery & 307 & \multirow{2}{*}{\multicolumn{4}{|c|}{ 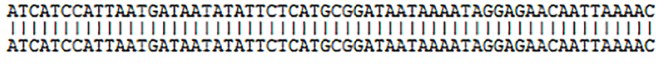 }} & \\
\hline bjet & 130265 & & & & & \\
\hline uery & 367 & \multirow{2}{*}{\multicolumn{4}{|c|}{ 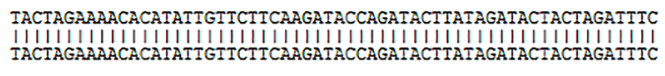 }} & 426 \\
\hline bbjet & 130205 & & & & & 130146 \\
\hline Query & 427 & \multirow{2}{*}{\multicolumn{4}{|c|}{ 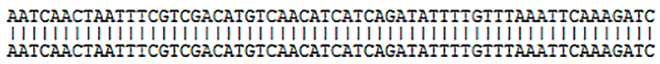 }} & 486 \\
\hline bुjet & 130145 & & & & & 130086 \\
\hline Query & 487 & \multirow{2}{*}{\multicolumn{4}{|c|}{ 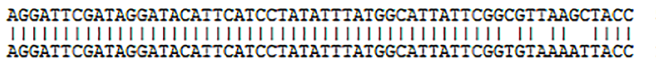 }} & 44 \\
\hline bjojet & 130085 & & & & & 30028 \\
\hline
\end{tabular}

Supplementary Figure 1. Sequence analysis of the PCR product alignment obtained from chorioallantoic membranes infected with Turkeypoxvirus, using the NCBI BLAST program. The product showed a 99\% identity with a Turkeypoxvirus strain. 
On the other hand, not all pox infections in turkeys are caused by Turkeypoxvirus, as some reports exist of turkey flocks infected with the chicken pox virus (Fowlpoxvirus), that was identified as the causal agent through PCR and sequencing. ${ }^{21}$

Field reports in Mexico (unpublished observations) reveal pox outbreaks in turkey flocks known to have been immunized with commercially available chicken vaccines, showing that although effective against Fowlpoxvirus infections, these heterologous vaccines can be inefficient against Turkeypoxvirus, as demonstrated in this study.

Sera from the control group subjects lacked neutralizing antibodies against Turkeypoxvirus. Results from the seroneutralization test for immunized birds show an 11.7 neutralization dose $50 \%\left(\mathrm{ND}_{50}\right)$ titre for the heterologous vaccine and a $99.7 \mathrm{ND}_{50}$ titre for the homologous vaccine. The antibody titre produced in subjects vaccinated with the heterologous chicken virus was thus noticeably lower than that of subjects vaccinated with the homologous vaccine. This could have contributed to differences in protection rates observed between groups during the challenge with the field-isolated virus, as neutralizing antibodies are crucial to grant protection. ${ }^{22}$ It also indicates that the vaccine developed in this study afforded a greater protection against Turkeypoxvirus.

There was a single turkey chick that had been vaccinated with the commercially heterologous vaccine that did not develop signs or lesions after the challenge with the field-virus. This individual may have developed an adequate neutralizing antibody titre, hence granting it sufficient protection against the heterologous field-virus challenge. Nonetheless, since individual antibody titres were not obtained in this study, it is not possible to assert if this was indeed the case.

\section{Conclusions}

The results of this study show an effective protective capacity of a homologous Turkeypoxvirus vaccine produced from infected animal scabs and viral attenuation in chicken embryos. This homologous vaccine resulted in a greater protection rate than that obtained with a heterologous Fowlpoxvirus commercial vaccine when applied in three-week-old turkey chicks that were subsequently challenged with a field-isolated Turkeypoxvirus. 


\section{Acknowledgements}

We thank Ing. Gilberto Vázquez, MVZ Isaías Merino and MVZ Joel Vargas from the Centro de Fomento Agropecuario (CEFOA), gobierno de Tlaxcala, México, for the support provided for the realization of this study.

\section{References}

1. Quintana JA. Avitecnia: Manejo de las aves domésticas más comunes. 4th ed. México: Trillas; 2011.406 p.

2. Unión Nacional de Avicultores. Compendio de indicadores económicos del sector avícola 2020. una.org.mx. México; cited 2020 dec 10. Avialable from: https://una.org.mx/indicadores-economicos/

3. Swayne D, editor. Diseases of poultry. 13th ed. Hoboken, NJ: Wiley-Blackwell; 2013. $1341 \mathrm{p}$.

4. SADER. Yucatán, principal productor de pavo en México. México: SADER; 2018.

5. MacLachlan NJ, Dubovi EJ. Fenner S. Veterinary viroligy. 5th ed. Cambridge, MS: Academic Press; 2016. 602 p.

6. Lüschow D, Hoffmann T, Hafez HM. Differentiation of avian poxvirus strains on the basis of nucleotide sequences of $4 \mathrm{~b}$ gene fragment. Avian Dis. 2004;48(3):453-62.

7. Gyuranecz M, Foster JT, Dan A, Ip HS, Egstad KF, Parker PG, et al. Worldwide phylogenetic relationship of avian poxviruses. J Virol. 2013;87(9):4938-51.

8. Tadese T, Reed WM. Use of restriction fragment length polymorphism, immunoblotting, and polymerase chain reaction in the differentiation of avian poxviruses. J Vet Diagnostic Investig. 2003;15(2):141-50.

9. Afonso CL, Tulman ER, Lu Z, Zsak L, Kutish GF, Rock DL. The genome of fowlpox virus. J Virol. 2000;74(8):3815-31.

10. Tulman ER, Afonso CL, Lu Z, Zsak L, Kutish GF, Rock DL. The genome of canarypox virus. J Virol. 2004;78(1):353-66.

11. Winterfield RW, Reed W. Avian pox: infection and immunity with quail, psittacine, fowl, and pigeon pox viruses. Poult Sci. 1985;64(1):65-70.

12. Sánchez $A$, Valdés LM, Rangel LE, Cobos L. Evaluación del efecto protector de una autovacuna elaborada a partir de poxvirus de palomas. Arch Med Vet. 2012;86:81-6.

13. Gelenczei EF, Lasher HN. Comparative studies of cell-culture-propagated avian pox viruses in chickens and turkeys. Avian Dis. 1968;12(1):142-50.

14. Purchase HG. A laboratory manual for the isolation and identification of avian pathogens. 5th ed. Madison, WI: OmniPress Inc; 1990. 331 p.

15. Lee $\mathrm{LH}$, Lee $\mathrm{KH}$. Application of the polymerase chain reaction for the diagnosis of fowl poxvirus infection. J Virol Methods. 1997;63(1-2):113-9.

16. Sanger $F$, Nicklen $S$, Coulson A. DNA sequencing with chain-terminating. Proc Natl Acad Sci USA. 1977;74(12):5463-7.

17. Reed $\mathrm{LJ}$, Muench $\mathrm{H}$. A simple method of estimating fifty per cent endpoints. Am J Epidemiol. 1938;27(3):493-7.

18. Murphy FA, J Gibb, C Horzinek JS. Laboratory diagnosis of viral diseases. 3a ed. Murphy FA, editor. Veterinary virology. California: Academic Press California; 1999. p. 216-8.

19. Winterfield RW, Reed WM, Thacker HL. Infection and immunity with a virus isolate from turkeys. Poult Sci. 1984;64:2076-80. 
20. Sarma G, Kersting BA, Spina G. Vaccination of 1-day-old turkey poults with fowlpox vaccine by subcutaneous route. Avian Dis. 2015;59(3):419-21.

21. Hess C, Maegdefrau-Pollan B, Bilic I, Liebhart D, Richter S, Mitsch P, et al. Outbreak of cutaneous form of poxvirus on a commercial turkey farm caused by the species fowlpox. Avian Dis Dig. 2011;6(4):714-8.

22. Zinkernagel RM, LaMarre A, Ciurea A, Hunziker L, Ochsenbein AF, McCoy KD. Neutralizing antiviral antibody responses. Adv Immunol. 2001;79:1-53. 